\title{
Presupposition and Policing in Complex Demonstratives
}

\section{Citation}

Glanzberg, Michael and Susanna Siegel. 2006. Presupposition and Policing in Complex Demonstratives. Nous 40, no. 1: 1-42.

\section{Published Version}

http://dx.doi.org/10.1111/j.0029-4624.2006.00600.x

\section{Permanent link}

http://nrs.harvard.edu/urn-3:HUL.InstRepos:3198693

\section{Terms of Use}

This article was downloaded from Harvard University's DASH repository, and is made available under the terms and conditions applicable to Other Posted Material, as set forth at http:// nrs.harvard.edu/urn-3:HUL.InstRepos:dash.current.terms-of-use\#LAA

\section{Share Your Story}

The Harvard community has made this article openly available.

Please share how this access benefits you. Submit a story.

\section{Accessibility}


Presupposition and Policing in Complex Demonstratives

Forthcoming in Nous

Michael Glanzberg (Univeristy of Toronto) and Susanna Siegel (Harvard)

January, 2004

The expressions this cat and that glove with a hole are complex demonstratives. In this paper, we defend a thesis about complex demonstratives. The thesis we defend concerns the role of the nominal (e.g., cat and glove with a hole) in a central class of uses. In the utterances at issue, we argue, the nominal $F$ in that $F$ plays a policing role: no proposition is semantically expressed by the utterance, if the object appropriated by the speaker's use of that $F$ fails to be F. We'll call this nominal policing. ${ }^{1[1]}$

In characterizing nominal policing, we introduced the concept of an appropriated object. Roughly, a speaker's use of that $F$ appropriates an object, if the speaker demonstrates that object, where demonstrations can include both publicly observable gestures by the speaker as well as speaker intentions. For example, if a speaker says That car is better than that car, successively pointing at and intending to talk about two cars in plain view, with each use of that car the speaker appropriates a different object. In this case, the object is a car both times. If in place of one of the cars, there was a boat, but the speaker's intentions and gestures of pointing remained the same, the speaker would appropriate a boat by one of her uses of that car. Nominal policing predicts that the speaker's utterance in this case would fail to semantically express a proposition.

The thesis of nominal policing has been a focal point of debate within the literature on complex demonstratives. It has been defended by David Braun (1994) and Emma Borg (2000), while Richard Larson and Gabriel Segal (1995) have suggested that it is false. ${ }^{2[2]}$ Much of this debate has relied upon the view that complex demonstratives, like bare demonstratives, are referring expressions, and paradigms of direct reference at that. If such a view is assumed, then at least part of the semantic contribution of a use of a complex demonstrative is its referent, and the crucial question becomes what, if any, semantic contribution the complex demonstrative can make beyond its referent. Policing, or the denial of policing, become theses about the status of this additional contribution. ${ }^{[3]}$

${ }^{1[1]}$ We put linguistic items in italics, and their corresponding semantic values in upright text.

${ }^{2[2]}$ Braun's view is a bit more subtle than we suggest: we say that the utterance fails to semantically express a proposition due to the nominal failing to be satisfied, whereas Braun would say that it expresses a gappy proposition, which is in turn either false or truth-valueless.

3[3] The locus classicus for direct reference is David Kaplan's

"Demonstratives" (1977/1989). There he says relatively little about complex demonstratives. As Braun (1994) remarks, the view of "Demonstratives" appears to imply policing. Braun's own paper offers a proposal compatible with Kaplan's that does include policing (cf. note 2 ). 
Now, the nominal in complex demonstratives can play a policing role, even if complex demonstratives are not directly referential. Recently, philosophers have begun to consider seriously the view that complex demonstratives are quantificational, where this is held to exclude their being devices of reference (direct or otherwise). ${ }^{4[4]}$ Our defense of nominal policing, unlike previous ones, is neutral on whether uses of complex demonstratives are referring expressions (as direct reference theorists hold), quantificational expressions (as King has proposed), or discourse anaphors in a dynamic semantics (as Craige Roberts (2002) has argued). This neutrality is not a lack of interest, and its point is not simply to avoid a premise which some have recently denied. Rather, we think that understanding what underlies nominal policing is fundamental to understanding the behavior of complex demonstratives, and in particular, the behavior that makes them appear referential. We will suggest that this behavior itself can be understood without supposing that complex demonstratives have the semantics of referring expressions.

Our defense of nominal policing will focus on a certain sort of presupposition failure to which uses of complex demonstratives are prone, when the appropriated object fails to satisfy the nominal. We argue on independent grounds that presupposition failure of this sort is tantamount to failure to semantically express a proposition. This will be central to our defense of nominal policing.

The discussion will proceed as follows. After some preliminary remarks in Section 1, in Section 2 we consider and reject the view that the nominal in complex demonstratives plays no truth-conditional role whatsoever, and some other related views. In Section 3, we present the core evidence for nominal policing. In Section 4, we argue that what appear to be some counterexamples to nominal policing do not really enjoy this status. We conclude the discussion in Section 5 with a speculation: perhaps referring expression as they have traditionally been understood do not form a genuine semantic category.

\subsection{Preliminaries}

Two things need explaining right away: the class of utterances at issue, and the notion of appropriation that occurs in our definition of nominal policing.

First, we will focus on a range of uses of complex demonstratives: expressions of the form that $F$. The nominal $F$ can itself be complex, as in that large house or that glove with a hole in it or that car which I saw the other day. The uses with which we will primarily be concerned are perceptual uses: those in which the speaker (and usually the hearer) perceives an object, upon which she thinks the truth or falsity of the utterance depends. These are paradigmatic uses of demonstratives. We will call them "classic

4[4] This recent consideration was spurred by Jeffrey King (1999), which attacks the view that complex demonstratives are devices of direct reference and defends the view that they are quantificational. See also King (2001a) and Lepore and Ludwig (2000). 
perceptual uses," and we will call the utterances in which they occur "perceptual demonstrative utterances." $"[5]$

We focus on classic perceptual uses because they exemplify what many have taken to be the paradigmatic behavior of referring expressions. For instance, when they occur in an utterance that has a truth-value, they are rigid. However, as we mentioned, our defense of nominal policing does not require any stance on the semantic category to which complex demonstratives belong.

Second, our central claim is nominal policing:

If the object appropriated by the speaker's use of that $F$ in a perceptual

demonstrative utterance is not $\mathrm{F}$, then the utterance fails to semantically express a proposition.

'Appropriation' is our term for the contextual supplement required by uses of complex demonstratives. Both bare and complex demonstratives require some sort of supplement from the context. In the case of complex demonstratives, the nature of this supplement is illustrated by the following contrast. Consider an utterance of:

1. 1. That key is bigger than that key.

Suppose the speaker successively points to and intends to talk about two keys in plain view. Contrast an utterance under the same circumstances of:

2. 2. \#The key is bigger than the key. ${ }^{6[6]}$

The latter is markedly infelicitous.

The contrast just drawn between complex demonstratives and definite descriptions suggests that the contextual supplement needed for complex demonstratives differs from whatever sort may be needed in the case of definite descriptions. ${ }^{77]}$ An utterance of (2) could be infelicitous, even when the speaker successively points to and intends to talk about two keys, both of which are already conversationally salient. ${ }^{8[8]}$

${ }^{5[5]}$ Readers of Gareth Evans (1982) will recognize classic perceptual uses as a subclass of the uses to which demonstrative expressions can be put, even disregarding the kinds of quantificational examples presented by King (2001a).

${ }^{6[6]}$ We use '\#' to indicate markedly defective utterances. '?' indicates marginally defective utterances. We take judgments of such defectiveness by native speakers to be on par with judgments of grammaticality as data for semantic theorizing.

7[7] We owe this point King (2001a, Ch. 2).

${ }^{8[8]}$ In some cases of definite descriptions as discourse anaphors, we can have a weakened effect. Consider:

(i) ?Whenever a new mobster tries to muscle in on an old mobster's territory, the mobster threatens the mobster.

(This is similar to the sort of examples attributed to Hans Kamp (cf. Heim 1990).) It is clearly preferable to say:

(ii) Whenever a new mobster tried to muscle in on an old mobster's territory, the OLD mobster threatens the NEW mobster. 
Here is a heuristic. A speaker appropriates an object o by the use of a complex demonstrative, if she stands to o in a relation of the sort that would suffice for her to refer to o by using a bare demonstrative. Some candidates for this relation include intending to refer to o by the use of a demonstrative expression, and using publically accessible cues, such as pointing, to indicate $0 .{ }^{9[9]}$ This is just a heuristic, as we wish to remain neutral on what sorts of facts about the context make it the case that by her use of that $F$, a speaker appropriates one object rather than another, or rather than nothing at all.

Our neutrality on the mechanism of appropriation makes us neutral on a subtle question concerning the role that the nominal plays in appropriation. There seem to be cases where the nominal is quite prominent in appropriation: for instance, cases in which the speaker cannot make clear what object she wants to talk about by using a bare demonstrative. If the mechanism of appropriation is the speaker's intention, then appropriation proceeds independently of the use of the nominal, and in these cases the nominal will play a merely epistemic role, enabling addressees to discern which object the speaker has appropriated. In contrast, suppose the mechanism of appropriation is a set of publically accessible cues. This opens the possibility that the use of the nominal plays a constitutive role in appropriation: a role that not merely enables the addressee to discern which object is appropriated, but furthermore determines which object this is.

Because we are neutral on the mechanism of appropriation, we are neutral on whether the nominal plays a constitutive or a merely epistemic role in this sort of case. Whatever the nature is of the contextual supplement needed by complex demonstratives, it is clear that some such supplement is needed. 'Appropriation' is our term for the supplement, whatever it is. We thus content ourselves with a functional characterization of appropriation.

Given how we have defined the class of classic perceptual uses of demonstratives, we may expect the appropriated object in such uses to be something the speaker perceives, and in the simplest cases, we may expect that it is common ground between speaker and hearer which object that is. However, we wish to stress that appropriation is fundamentally a linguistic notion, not a notion in the philosophy of mind. Appropriation is achieved in acceptable uses of complex demonstratives. Being appropriated is a status something can only have in a context of discourse.

Our definition of nominal policing alludes to the object appropriated by the speaker's use of that $F$. Whatever underlies appropriation, we stipulate that if any object is appropriated by a speaker's use of that $F$ in a perceptual demonstrative utterance, then a unique object is. Something analogous will hold for plural demonstratives. ${ }^{10[10]}$

So far, we have spoken as if there is such a thing as a speaker appropriating, by her use of a complex demonstrative, an object that does not satisfy that complex

${ }^{9[9]}$ For discussion of what sorts of factors underlie reference in the case of bare demonstratives, see Siegel (2002).

${ }^{10[10]}$ We will generally restrict our attention to singular demonstratives, so we will not formulate the condition for plural demonstratives here. 
demonstrative's nominal. (Our very definition of nominal policing assumes that this is possible). But logical space has room for a theory of appropriation on which an object can be appropriated by a speaker's use of a complex demonstrative expression, only if that object satisfies that expression's nominal. On this theory, cases of the sort described in the definition of nominal policing are not possible. Since we said we were neutral on the mechanisms of appropriation, and since the theory just mentioned is a theory in part about those mechanisms, this theory deserves comment.

Martin Davies (1982) has defended a theory about complex demonstratives according to which there is no such thing as a speaker's appropriating an object that is not $F$ by the use of that $F$. Like nominal policing, Davies's view rules out that a proposition

may be expressed by an utterance of That $F$ is $G$ when there is no appropriated object that is $\mathrm{F}$. Indeed, the view seems to give the same predictions about truth-conditions in the context of utterance: an utterance of That $F$ is $G$ will be true only if the appropriated object is $\mathrm{F}$ (in the context of utterance) and $\mathrm{G}$, and it will be false only if the appropriated object is $\mathrm{F}$ and not $\mathrm{G}$. This view, then, makes similar predictions to ours, but in a way that makes policing appear trivial. The reasons Davies offers for his view are ones we reject. ${ }^{1111]}$ Moreover, we will present examples below which are clear cases of appropriation in which the nominal is not satisfied.

Though we have given only a functional characterization of appropriation, we believe this is enough to proceed to ask what role the nominal in a complex demonstrative plays, especially when an object is appropriated.

\section{Inertness and shiftiness in complex demonstratives}

The notion of appropriation suggests one reason why nominal policing is contentious. If we think of a demonstrative as a device of reference, then it may appear that appropriation of an object suffices to secure its referent, and that there is no truthconditional role left for the nominal to play. The nominal appears to be, as we shall say, truth-conditionally inert. Let the strong inertness thesis be the following:

A perceptual demonstrative utterance of That $F$ is $G$ is true in the context of utterance if and only if the appropriated object is G.

${ }^{11}[11]$ We take issue with a claim in the philosophy of mind made by Davies (Davies 1982, though from recent conversations we think his current view is different). Davies claims that a subject cannot succeed in perceiving an object without "employing a sortal concept" in an "individuative role" (1982, p. 292). His reasons are broadly Quinean: he thinks there is no fact of the matter about whether one is perceptually representing a mereological sum of tomato-parts, or a time-slice of a tomato, or the front surface of a tomato, unless one "employs" a sortal concept that the object in fact satisfies, such as the concept 'tomato'. Against this, we think that perceptual representations can succeed in representing tomatoes even if the subject "employs" no sortal concept that the tomato satisfies. (Perhaps the perceiver is under an illusion that it is a superball, or perhaps the tomato is in a convincing baseball costume.) 
Larson and Segal (1995, p. 213) and Neale (1993) express some sympathy for this thesis (though they do not offer a full-fledged defense of it), and it is defended by Stephen Schiffer (1981). According to the strong inertness thesis, no matter what the value of $F$ is, the truth of an utterance of That $F$ is $G$ depends on and only on whether the appropriated object is G. To keep things simple, we have stated the thesis for a sentence of the form That $F$ is $G$. More generally, the strong inertness thesis holds that the semantic contribution of an occurrence of a complex demonstrative is determined entirely by the appropriated object, leaving no semantic role of any sort for the nominal.

In principle, the strong inertness thesis could be combined with a proviso about appropriation to the effect that something can be appropriated by a use of a complex demonstrative only if it satisfies the nominal (as Davies 1982 proposed). As we mentioned earlier, this view would seem to make the same predictions as nominal policing: when no object is appropriated, no proposition is expressed; utterances of that $F$ is $G$ have truth values only if the object the speaker wants to talk about is $\mathrm{F}$; they are true if that object is $\mathrm{G}$ and false if it is not $\mathrm{G}$.

Without this proviso concerning appropriation, the strong inertness thesis is incompatible with nominal policing. Following our remarks at the end of Section 1, in the rest of this paper, when we discuss the strong inertness thesis, we will assume that the version of the thesis at issue is free of this proviso. We will thus allow that a speaker may appropriate an object by using a complex demonstrative, when the object does not satisfy the complex demonstrative's nominal. Indeed, as we mentioned in Section 1, we will discuss at length examples which make our assumption appear to be the only natural one.

The strong inertness thesis takes it to be sufficient for the truth of an utterance of That $F$ is $G$ that the appropriated object be $\mathrm{G}$, while policing requires that it satisfy $F$ for the utterance to have a truth value at all. The denial of the strong inertness thesis is compatible with nominal policing, but does not require it. One sort of semantics that denies the strong inertness thesis allows that in a context where the object appropriated is not $\mathrm{F}$, the utterance is false. In contrast, if nominal policing holds, then such an utterance fails to semantically express a proposition at all. ${ }^{12[12]}$ All the same, in our case for nominal policing, the first order of business is to argue against the strong inertness thesis.

${ }^{12[12]}$ We are counting policing as a truth-conditional role for the nominal. Policing holds that the nominal plays a non-trivial role in truth-conditional semantics, in that it plays a semantically specified role in determining whether a proposition is expressed. Rather than gloss this situation as one in which the nominal has no truth-conditional role, we prefer to describe it as one in which the nominal plays a truth-conditional role (though as we shall say later, one that is entirely presuppositional) because this role is encoded in the truth-conditional semantics. Moreover, policing stands in contrast to the view that the role of the nominal is purely one of aiding the hearer's understanding of the proposition expressed.

Although it is not built into the definition of nominal policing that policing is the only truth-conditional role for the nominal, we think that it is. (Here we concur with Braun 1994 and Borg 2000.) 
The strong inertness thesis is motivated by a sort of case made familiar by discussions of referential uses of definite descriptions (borrowing terminology from Keith Donnellan 1966). The referential uses in question are uses of the definite description the $F$ where the intended referent does not satisfy $F$. Despite the fact that the speaker in Donnellan's classic examples misdescribes the object she intends to talk about, communication proceeds unimpeded. In one of the examples, a speaker at a party says:

3. The man in the corner drinking a martini is happy.

The speaker is pointing at and intending to talk about a man who is drinking water. Yet communication appears to be unimpeded. Thus, part of the nominal seems to be communicatively inert. It seems to be superfluous in indicating the man about whom the speaker intends to communicate.

In some contexts, classic perceptual uses of complex demonstratives exhibit these same features. A fox is nosing its way through the garbage. An onlooker who mistakes it for a badger says to someone witnessing the scene:

4. That badger is hungry.

In some such contexts, the nominal badger is not needed to enable the hearer to understand what the speaker intends to communicate. It is not needed, for instance, if the fox is already available to be the topic of the conversation by being mutually acknowledged as visually prominent. ${ }^{13[13]}$ In general, if other factors already make it obvious to the addressee which object the speaker has appropriated in her use of that badger, then the nominal badger is not needed to serve this purpose.

The strong inertness thesis is motivated by the idea that communicative inertness indicates truth-conditional inertness. It takes those uses of complex demonstratives in which the nominal is communicatively inert as the paradigm classic perceptual uses.

It is tempting to dismiss strong inertness out of hand, as one might think that a predicate could not be semantically inert in a sentence. This idea is expressed by the following argument:

In a compositional semantics, the semantic value of a sentence is a function of the semantic values of its constituents. If the nominal $F$ in a complex demonstrative that $F$ were inert, $F$ could not make its usual contribution to the truth conditions of sentences of the form, for instance, a is $F$.

Call this the semantic contribution argument. Borg (2000, p. 239) makes this argument in criticizing Larson and Segal's support for the strong inertness thesis:

[W] know that the parts treated as otiose [by the strong inertness thesis] must be treated as meaningful elsewhere in our theory; that is to say, our semantic theory independently requires rules for predicate expressions, which will be called into play when a predicate term appears in any other context . Yet, when appearing concatenated with a demonstrative term, these meaning rules must simply be bypassed; despite the superficial

13[13] Example (4) is close to one given by Larson and Segal (1995, p. 213) in their sympathetic discussion of inertness theses. 
similarity of that $F$ and the $F$, the proponent of [the semantic inertness

thesis] must hold that our theory treats only the latter as possessing a structured meaning... ${ }^{14[14]}$

Though we deny the strong inertness thesis, we think the semantic contribution argument against it is misguided. The argument conflates the input to semantic composition with the output of semantic composition. This is a mistake. It is not difficult to give a semantics of complex demonstratives which allows the nominal both to have its usual semantic value, and yet to be inert when it is part of a complex demonstrative.

To illustrate this point, we need to consider a fragment of a semantic theory. Let us stipulate, not implausibly, that a sentence of the form That $F$ is $G$ has the structure [[[that $][\mathrm{F}]]$ is $\mathrm{G}]$. We shall take the predicates $F$ and $G$ to have their usual semantic types, as functions from objects to truth-values, and we shall assume that the only composition rule at work is functional application. It is relatively easy to arrive at a semantic value for that $F$ which is not anomalous, where that has as its semantic value a constant function on the value of $F$. In this case, that $F$ will deliver the same output, no matter what value $F$ has. This is compatible with the nominal $F$ having the same semantic value as it has in other constructions.

Rather than develop this theory in much more detail, let us consider what it predicts with respect to a use of an English sentence of the form That $F$ is $G$. Return to the scene with the garbage, in which a speaker mistakes a hungry fox for a hungry badger, and utters That badger is hungry (4). Let us first suppose that, for an occurrence of that as part of a classic perceptual use of a complex demonstrative, there is a function $a(c)$ which returns the appropriated object of the context of use $c$. Then the semantic value of that will be a constant function from the value of $F$ to $a(c)$. In notation, $[[\text { that }]]^{c}=\lambda F . a(c)$, where an expression inside double brackets superscripted with $c$ indicates the semantic value of that expression relative to the context $c$. Then, by applying function to argument, we can compute:

5. [[that badger is hungry $]]^{c=1}$ iff

$[[\text { hungry }]]^{c}\left([[\text { that badger }]]^{c}\right)=1$ iff hungry $(a(c))$

${ }^{14[14]}$ We have modified Borg's notation to fit our own. Josh Dever (2001) makes a somewhat similar criticism of inertness theses. Dever assumes (against the strong inertness thesis) that "the proposition that that $\mathrm{F}$ is $\mathrm{G}$ logically implies the proposition that some F is G." He then endorses what he calls a version of semantic innocence, which he says "insists that the predicate $F$ in that $F$ is $G$ make the standard $F$-type contribution to content, and hence guarantees the overlap of $F$-ness and $G$-ness that licenses the inference [from the proposition that that $F$ is $G$ ] to the proposition that some F is G" (p. 277, notation modified to fit our own). 
This is true if the object appropriated by the use of that badger has the property of being hungry. ${ }^{15[15]}$

In this fragment of a semantic theory, the nominal retains its usual semantic value. It nonetheless satisfies the strong inertness thesis, thanks to the unusual rule for that. Granted, the way in which the semantic value of that $F$ depends on the semantic value of $F$, in this fragment, is not very interesting. But it is compositional just the same. This illustrates that it is possible to give a compositional semantics for That $F$ is $G$ with the following three features. First, the truth or falsity of a use of That $F$ is $G$ does not depend on whether that object is F; second, the semantic values of nominals need not differ from what they are in other constructions; third, it uses only entirely standard modes of semantic composition (indeed, only functional application). The fact that the semantic theory sketched has these three features shows that the semantic contribution argument does not threaten the strong inertness thesis. For all the semantic contribution argument shows, that thesis is perfectly plausible.

Although the strong inertness thesis is not threatened by the semantic contribution argument, it is threatened by other considerations - notably, by some pragmatic considerations. Return once more to the fox in the garbage. Suppose that this time, the speaker mistakes the fox for a secret agent. The fox does not look like a secret agent, in the way in which gasoline looks like water. But the speaker has a set of idiosyncratic beliefs: he believes that a new sort of secret agent has come to patrol the garbage, on a hunt for potentially useful information, and that the secret agent has the capacity to make himself look exactly like a fox. ${ }^{16[16]}$ Let us suppose that the speaker in this situation is making two sets of mistakes. First, his beliefs about the disguises of secret agents are mistaken: there are no such secret agents who can disguise themselves as foxes. A fortiori the fox in the garbage is not a secret agent. Second, let us suppose, the speaker mistakenly believes that his addressee shares these beliefs. In fact, the addressee knows that the creature in the garbage is a fox, and knows as well that there are no secret agents that can disguise themselves in the way the speaker imagines.

In such a context, consider the speaker's utterance:

6. \#That secret agent is hungry.

He takes this to be both appropriate and true. More exactly, he thinks that the nominal secret agent is an epistemically useful nominal to use, in order to communicate what he wants to about the creature he sees in the garbage.

${ }^{15[15]}$ We have somewhat arbitrarily chosen to sketch a semantics in which [[that $\left.]\right]^{c}$ has type $<<\mathrm{e}, \mathrm{t}>$,e $>$, taking as input a predicate and giving as output an individual. It would be easy to give similar treatment making it a full-fledged generalized quantifier with type $<<\mathrm{e}, \mathrm{t}>,<<\mathrm{e}, \mathrm{t}>, \mathrm{t}>>$. Nothing we say is sensitive to this difference.

${ }^{16[16]}$ So in a sense of look different from that in gasoline looks like water, the fox does look like a secret agent: it looks to the speaker as (the speaker believes) a secret agent would look under the circumstances that speaker believes himself to be in. 
Once apprised of the facts, native English speakers do not tend to regard as true the speaker's utterance of (6) in the context described. We take this to be a datum. There seem to be three possible explanations for it: (i) something is appropriated by the speaker's use of that secret agent, and the nominal plays a truth-conditional role; (ii) something is appropriated by the speaker's use of that secret agent, and the utterance is true, and in judging that it is not true, speakers are confusing lack of truth with pragmatic inappropriateness; (iii) nothing is appropriated by the speaker's use of that secret agent.

Only explanation (ii) is compatible with the strong inertness thesis. According to (i), since the nominal plays a truth-conditional role, the utterance is either false or truthvalue-less, and according to (iii), the utterance is truth-valueless because nothing is appropriated. Given that only (ii) is compatible with the strong inertness thesis, the weaker the case for explanation (ii), the weaker the reason to believe the strong inertness thesis.

Explanation (ii) must posit a merely pragmatic role for the nominal in (6). It cannot be part of this role to break appropriation, since by hypothesis the fox is appropriated by the speaker's use of that secret agent. What makes explanation (ii) inferior to (i) and (iii) is that there is no such role for the nominal to play. There does not seem to be any epistemic role for it to play in helping the addressee figure out which thing is appropriated. It is easy to imagine the case in such a way that it is obvious to the addressee that the speaker is pointing to and intending to talk about the fox. (Indeed, this is the way we assumed the case to be.) Thus, in (6) so described, there is no further question about which object the speaker wishes to say is hungry, and so no epistemic role for the nominal to play.

There is a different version of explanation (ii) that might be proposed by the proponent of the strong inertness thesis. According to this explanation, the utterance of (6) is pragmatically odd, not because of its semantically expressed content, but because of an implicature it generates: namely, the false implicature that o (where o is the appropriated object) is a secret agent. This putatively implicated proposition may itself suffer from some additional pragmatic oddity, but neither oddity nor falsehood are features of the proposition semantically expressed by (6). ${ }^{17[17]}$ We have two objections to this view.

First, recall that one of the hallmarks of a conversational implicature is that it is cancelable. To take, for instance, a typical scalar implicature:

7. Some of John's children are sleeping - in fact, they all are.

The usual implicature of the existential quantifier is canceled by the second part of the sentence. Such explicit cancellations are never contradictory. But now consider:

8. \# That secret agent is hungry, but it is not a secret agent.

${ }^{17[17]}$ A position along these lines is discussed, cautiously, by Neale (1993). 
This is not merely inappropriate, it is apparently contradictory. ${ }^{18[18]}$ We thus do not see the hallmark of conversational implicature in the relation between the proposition expressed by (6) and the proposition that o is a secret agent.

Second, on the proposed view, there has to be some pragmatic mechanism that takes as input the putatively semantically expressed (and true) proposition that $\mathrm{o}$ is hungry, and delivers as output the putatively implicated proposition that o is a secret agent. On Grice's original formulation (1975), the mechanism is explained via the familiar maxims of quality (do not say what you take to be false or evidentially unsupported), quantity (do not be overly or insufficiently informative), relation (be relevant), and manner (do not be obscure, prolix, or disorderly). But none of these maxims is violated if an utterance of (6) simply conveys the semantically expressed proposition. It is clear that neither quality nor quantity is violated. Likewise relation is not (as the appropriated object is sufficiently relevant).

The only sort of implicature in the Gricean scheme for which we might find a mechanism then seems to be a manner implicature. The maxim of manner instructs us not to be obscure, prolix, or disorderly. It is not always easy to know if this would be violated, but it might be suggested that the mere use of a nominal is sufficient prolixity to trigger a manner implicature. Our objection from cancelabilty readily applies here. Like all implicatures, manner implicatures are cancelable, but manner implicatures are especially easy to cancel, as there is an easy, uniform means of cancellation: you just say, 'but I did not mean to suggest anything by that, other than ...'.

Furthermore, there are striking disanalogies between the putative implicature generated by (6) and the paradigmatic manner implicatures. In paradigmatic manner implicatures, the manner of expression triggers the implicature, as in Grice's example:

9. She produced a series of sounds that correspond closely with score of "The Star-Spangled Banner."

As Grice points out, if a reviewer chose to write (9) as opposed to "She sang 'The StarSpangled Banner'," the implication would be that the singer sung badly. This implicature is thus triggered, not by the fact being reported, but rather by the manner in which it is expressed. But not any occurrences of linguistic material suffice for manner implicatures. Compare (9) with:

10. 10. A. She sang the national anthem.

B. B. She sang the country's national anthem.

Only (9) triggers any sort of manner implicature. As a number of discussion of implicature have shown, to generate a manner implicature, some sort of marked phrase is required, where sufficiently prolixity or disorder can suffice for markedness. ${ }^{19}[19]$ On the basis of the presence of a marked phrase, speakers calculate a manner implicature

${ }^{18[18]}$ An analogous objection applies to the view that utterances of The $F$ is $G$, with the $F$ used referentially, implicate that o is $\mathrm{F}$, where o is the thing that the referentially used definite description is used to talk about.

19[19] See, for instance, Horn (1989) and Levinson (2000). 
accordingly. But as we see with (14), the mere presence of linguistic material which is not strictly necessary for expressing a content is not sufficient to generate a manner implicature. It need not be sufficiently marked. Hence, there is no prima facie reason to think that the mere presence of a nominal triggers a manner implicature, and as our remarks on cancellation show, there is good reason to think it does not. ${ }^{20[20]}$

In response to this pragmatic criticism of the strong inertness thesis, a fan of the main idea behind the strong inertness thesis might try to weaken the thesis as follows:

There are some contexts in which a perceptual demonstrative utterance of

That $F$ is $G$ is true, if the appropriated object is $\mathrm{G}$ and not $\mathrm{F}$.

Whereas the strong inertness thesis says it is sufficient for an utterance of That $F$ is $G$ to be true, the appropriated object is $\mathrm{G}$, the weakened thesis allows that there are utterances of That $F$ is $G$ that are not true, even though the object appropriated by the use of that $F$ really is $\mathrm{G}$.

We shall call this the weakened inertness thesis. As formulated, the weakened inertness thesis is very weak: weak enough to be compatible with number of different theses about the semantics of complex demonstratives. But the basic point of any of them is the same. Call contexts like that of (4) (the fox/badger) reasonable: in such contexts, it is reasonable to take the appropriated object to satisfy the nominal. Call contexts like that of (6) (the fox/secret agent) unreasonable: in these contexts, it is unreasonable to take the appropriated object to satisfy the nominal. The point of the weakened inertness thesis is to have the nominal behave as if inert in reasonable contexts like (4), but not in unreasonable contexts like (6). The nominal will thus appear to be inert in reasonable contexts, but will play a stronger role in unreasonable ones. We will consider three ways of implementing the weakened inertness thesis.

The first stays as close as possible to the model of the strong inertness thesis, in that it applies the inertness semantics. But it applies the semantics selectively, taking it to apply only in reasonable contexts. On this view, in reasonable contexts, the nominal combines by a rule like the one discussed for strong inertness; in unreasonable contexts, it combines by a rule that applies the nominal's default value. So this option appeals to

20[20] Similar points can be made, mutatis mutandis, for modern re-workings of the Gricean scheme, such as those in Horn (1989) and Levinson(2000). We believe the point to be quite general. There is nothing uncooperative about conveying the semantically expressed proposition, nor is there anything marked about the use of the nominal. Hence, there is no way to calculate an implicature in any way based on the cooperative principle.

According to the strong inertness thesis, (6) means the same as That is hungry, so the fan of the proposal under attack might insist that comparison with the bare demonstrative, that secret agent is prolix after all. This still does not appear to be sufficient markedness to generate an implicature. If it were, then the view would have to predict that any use of a complex demonstrative would be marked, and generate a manner implicature. This prediction is a non-starter in cases where it is not already obvious (independently of her use of a complex demonstrative) which object the speaker wishes to appropriate. 
context-dependent rules of composition: which composition rules apply, on this view, depends on whether the context is reasonable or unreasonable. Rather than introduce context-dependence via a rule, it makes what rule applies itself context-dependent. ${ }^{21[21]}$ We find this highly implausible, and are inclined to dismiss it out of hand. (For any readers not so inclined, the objection we raise against the second proposal will apply to this one as well).

The second option avoids appealing to context-dependent composition rules. Instead, on this option, what is sensitive to whether the context is reasonable or unreasonable is the nominal itself, rather than any special composition rule. On this view, in reasonable contexts, such as (4), the nominal contributes a sufficiently general property that the appropriated object satisfies it. And in unreasonable contexts, such as (6), it makes its normal contribution. One cost of avoiding context-dependent rules is that the nominal is never genuinely inert, as it is according to the strong inertness thesis. For in both kinds of context, it contributes a property, albeit a less restrictive one in reasonable contexts. The weakened inertness thesis is weak enough that this option satisfies it.

Like the context-dependent composition rules invoked by the first option, the context dependence invoked here is not very plausible, prima facie. Consider a perceptual demonstrative utterance where the nominal contains the clearly context-dependent expression tall:

11. That tall secret agent is hungry.

In the unreasonable context of (6), the nominal would contribute the usual value of tall secret agent, where the value of tall is fixed in part by the context. Now, consider a reasonable context for (11). There is a five-foot tall man wearing a trench coat and a hat. By a trick of the light, he looks to be about six feet tall, and he is not in fact a secret agent, he is a banker. The view we are considering predicts that in this context, the nominal tall secret agent will contribute its less restrictive value. Assuming that the value of tall secret agent is the intersection of the values of tall and of secret agent, this option predicts that the context extends the extension of tall to five feet, and extends the extension of secret agent to include bankers. But nothing that we know about how the value of tall depends on the context gives any reason to expect that its value will change in this way. More generally, nothing we know on independent grounds about the context-

21[21] Technically, it is easy enough to formulate such rules. A modification of the rule in (5) would not be difficult. To highlight our neutrality on just what the semantics of complex demonstratives must be, we could also give a semantics along the following lines. [[That] $]^{c}=\lambda F \lambda G . \Phi^{c}(F, G)$. For contexts like that of (4), where inertness is desired, $\Phi^{c}(F, G)=G(a(c))$, getting the same result as (5) above. For contexts where we do not want inertness, like that of (6), we could have $\Phi^{c}(F, G)=F(a(c)) \& G(a(c))$. Other options, more in line with nominal policing, are also available. Note that this semantics is context dependent, not in the sense that the mode of composition depends on the syntactic environment, but that it depends on features of the context of utterance. 
sensitivity of such adjectives suggests that they are sensitive to whether a context is reasonable or unreasonable. ${ }^{22[22]}$

There are other reasons to think this second option makes false predictions. If sensitivity to whether a context is reasonable or unreasonable is an aspect of the contextdependence of the nominal, then it should appear independently of what determiner goes with the nominal. With this in mind, consider:

12. The badger is hungry.

In the reasonable context of (4), the second option predicts this will come out true. (It does not merely say that there is a true speaker meaning associated with the utterances; it says that the semantic value of the sentence in context is evaluated to truth). This appears wrong, and is predicted to be wrong on most theories of definite descriptions.

Let us turn to a third way of implementing the weakened inertness thesis. Whereas the previous option called for the nominal to shift its contribution between different uses of complex demonstratives, this option calls merely for shiftiness between nominal contributions in complex demonstratives, on the one hand, and nominal contributions in other constructions, on the other. It is, therefore, equally a view about the contributions of that and $F$ in that $F$. The single sort of contribution allegedly made by the nominal in complex demonstratives is this. The semantics of that converts the value of $F$ to reasonably taken to be an $F$, and the nominal then contributes this value in a policing role.

As with the previous option, the nominal's role is not inertness, as posited by the strong inertness thesis, since the nominal always makes some sort of semantic contribution. But it satisfies the weakened inertness thesis nonetheless. In reasonable contexts, That $F$ is $G$ will be true even if the appropriated object is not an F. This will be so because, by hypothesis of what reasonable contexts are, it is reasonably taken to be F.

22[22] A referee suggested that the fan of the weakened inertness thesis could abandon the assumption that in reasonable contexts, the rule works with extensions of both modifier and noun in complex nominals such as tall secret agent. Abandoning this assumption, the referee suggested, would allow nouns in reasonable contexts to contribute a more general property (such as the property of being an agent), while adjectives change their contribution to something innocuous mimicking inertness. The motivation behind this proposal is to preserve the intuition that the property contributed by whole nominal in that tall secret agent is simply the property of being an agent.

The point we raised against the second version applies to this one as well. Both versions have it that the adjective is sensitive to whether the context is reasonable or not, and nothing we know about the context-sensitivity of adjectives suggests that they are sensitive to this contrast. For instance, tall is sensitive to a number of contextual features, both of extra-linguistic context, and of its linguistic environment. But none of this amounts to sensitivity to whether a context is reasonable or unreasonable. (See Kennedy 1997 for recent work on the context dependence of adjectives like tall.) Even more generally, where we understand context-dependence, we do not see sensitivity to whether the context is reasonable or unreasonable. 
The third option may appear to circumvent the problems with the previous proposal, as it avoids context dependent rules of composition, and does not ask the nominal to shift its value between uses of complex demonstratives.

Our objection to the third option considers the following pair of sentences:

13. A. That mouse is hungry.

B. That thing reasonably taken to be a mouse is hungry.

According to the third option, the complex demonstrative construction makes the extension of mouse expand to include things (in that context) reasonably taken to be mice. So it predicts that (13A) and (13B) will be synonymous. ${ }^{23[23]}$

This prediction appears to be false. Suppose we are in a zoology lecture. The lecturer informs us that mice and shrews can be reasonably mistaken for one another, and that even experts sometimes make mistakes. But the lecturer goes on to show us one animal of each kind, and shows us precisely how to tell by looking which one is which. She can certainly go on to say (13B) twice in succession, once pointing to the mouse, and once pointing to the shrew she has just explained can be reasonably taken for a mouse. Assuming the animals really are hungry, both utterances of (13B) are true. In contrast, we get no such judgment for the corresponding uses of (13A). There, when she is pointing at the shrew (which was just explained not to be a mouse), there is a strong judgment that her utterance of (13A) cannot be true. ${ }^{24[24]}$ More importantly, there is a strong differential judgment between (13A) and (13B). This is incompatible with the prediction that they are synonymous.

Let us summarize the dialectic so far. The strong and the weakened inertness theses are motivated by the imperviousness of communication to (some) misdescription. The strong inertness thesis has trouble with demonstrative utterances (of the form That $F$ is $G$ ) in which the object appropriated by the use of That $F$ is $\mathrm{G}$, yet in which speakers are strongly disinclined to assess the utterance as true. The weakened inertness thesis tries to accommodate these cases, but, we have argued, it cannot plausibly be implemented.

${ }^{23[23]}$ We are supposing that the rule that takes $F$ to reasonably taken to be an $F$ will take reasonably taken to be an $F$ to itself. The idea is to expand the nominal's extension in order to take into account the epistemic situation of the speaker using it. If the epistemic situation is already accounted for by the nominal, then iterating this process adds nothing. It is important keep in mind that the rule doesn't instruct us to add linguistic material. Adding linguistic material could lead to non-trivial iteration, but that's not what the proposal in question offers.

${ }^{24[24]}$ As with sentence (6) (That secret agent is hungry), one explanation for speakers' judgments that the sentence is not true is that speakers have confused lack of truth with pragmatic inappropriateness. We have already criticized this explanation (in the discussion of explanation (ii) in our original discussion of (6)), and in any case what matters here is the difference in judgments about (13A) and (13B), not whether those judgments are correct. 
If both the strong and the weakened inertness theses fail, then the remaining option is that the nominal plays a truth-conditional role of some sort. This would be either a policing role, or a role whereby an utterance of That $F$ is $G$ is false if the appropriated object is not $\mathrm{F}^{25[25]}$ We now argue directly for nominal policing.

\section{Presuppositional phenomena as evidence for nominal policing}

Our argument for nominal policing has the following three-step structure. First, we will

point out a glaring sort of semantic defect to which uses of bare demonstratives (this, that and their plurals) are prone. In the case of bare demonstratives, it is relatively easy for hearers to tell when this phenomenon is present, as the defect is something that can be readily observed. Aside from the striking feeling of defectiveness, however, there are also tests, involving the ways in which discourse may sensibly continue, by which one can detect this phenomenon. The second step of the argument is to present these tests.

In the third step, we move from bare demonstratives to complex demonstratives. We will argue, using the tests presented in the second step, that certain uses of complex demonstratives behave the same way as defective uses of bare demonstratives do: namely, uses in which the speaker appropriates an object that does not satisfy the nominal turn out (by the lights of the tests) to be just as defective as the defective uses of bare demonstratives. From the fact that the tests give the same results in both of these cases, we conclude that the same phenomenon of semantic defectiveness is present both times.

This will amount to an argument in favor of nominal policing. As will become clear as the discussion progresses, it will offer diagnostics for when an utterance fails to semantically express a proposition. When an appropriated object fails to satisfy a nominal, those diagnostics are met, and no proposition is expressed.

\subsection{Bare demonstratives}

Let us begin with the glaringly defective uses of bare demonstratives. Suppose a speaker points generally off into the distance and says:

14. \#That is a fine piano.

This utterance is defective. There are two important features of its defect. First, it seriously inhibits communication. Second, the reason it inhibits communication appears to be somehow semantic - it is not that the utterance is rendered irrelevant, off-topic, or opaque. In this case, it appears the utterance cannot completely determine the conditions in which the item referred to by the occurrence of the demonstrative that has the property of being a fine piano. There is no such object, so we fail to determine truth conditions in this sense.

In light of this, we shall describe this sort of situation as one in which no proposition is expressed by the utterance (as we likewise do in nominal-policing). This formulation is no doubt somewhat theory-laden. The situation could be described in slightly different (and equally theory-laden) ways. It could be described by saying a structured proposition is expressed, but is gappy, in virtue of missing a constituent

25[25] The latter view is defended by Richard (1993), and by Lepore and Ludwig (2000). 
corresponding to the noun phrase. ${ }^{26[26]}$ Alternatively, it could be described by saying a false proposition is expressed, but one that is false in a way distinctive of reference failure. (This is especially theory-laden, as the negation of the sentence would require the same distinctive falsehood status). No doubt, there are other options. ${ }^{27[27]}$

In light of the failure to determine truth conditions in the sense we described, we believe our preferred description is apt. But we also want to stress that for our concerns here, the theoretical differences between these various descriptions of the situation are comparatively minor. First of all, the judgment that there is something wrong in cases like (14) is very clear, and we take it to demonstrate the phenomenon in question, independently of any description we might choose. Moreover, each description agrees that the example exhibits some kind of grave semantic defect, be it lack of a proposition, incompleteness of a proposition, or a distinctively marked sort of falsehood corresponding to reference failure.

It will be useful to have a label for the defect at issue. We will call it p-infelicity ('p' for 'propositionless'). The term 'infelicity' is often used to indicate that something is inappropriate or unacceptable. The judgment that (14) is somehow defective is a clear case of a judgment of infelicity. There are many kinds of unacceptability, and 'pinfelicity' is a label for the sort displayed in the utterance of (14). ${ }^{28[28]}$

We now turn to the second step of our argument, in which we present tests that can detect cases of p-infelicity, such as the defect apparent in the utterance of (14) when the bare demonstrative is empty.

\subsection{Tests for p-infelicity}

The defective utterance of (14) is an example of a presupposition failure. The utterance of That is a fine piano presupposes that the demonstrative that indicates a unique contextually salient individual. It is the failure of this presupposition that leads to failure to express a proposition. The tests that detect p-infelicity will be tests for a certain sort of presupposition failure.

\footnotetext{
${ }^{26[26]}$ As noted earlier, this is Braun's (1994) view. Gappy propositions are further discussed in Braun (1993).
}

27[27] Michael Dummett (1959) discusses this option.

28[28] The notion of infelicity appears in J. L. Austin (1975) as a very general concept of inappropriateness which might attach to an utterance. Much of the more recent pragmatics literature, especially the literature on presupposition (e.g. Robert Stalnaker 1974; Lauri Karttunen 1974) concentrates on a more narrow notion of inappropriateness to assert or utter in a context. Irene Heim (1988) talks about whether a context "admits" a sentence. Infelicity in this sense remains strictly weaker than, for instance, uninterpretability. Our notion of infelicity is this latter, more narrow one. However, there is some reason to doubt that all infelicity even in this more narrow sense is $\mathrm{p}$ infelicity. For discussion of this, see Glanzberg (forthcoming b). 
Before elaborating the tests, it will be useful to comment on the notion of presupposition at issue. In linking presupposition to judgments of felicity, we are working with a pragmatic notion of presupposition. This sort of presupposition describes the requirements a sentence places upon a context for an utterance of the sentence to be felicitous in a context. Thus, sentence $S$ presupposes proposition $p$ if (and only if) a context must satisfy $p$ for an utterance of $S$ to be felicitous in it. A bare demonstrative triggers the presupposition that the context contain a contextually salient demonstrated individual, as an utterance of a sentence containing a bare demonstrative will not be felicitous unless this requirement is met. ${ }^{29[29]}$

The pragmatic notion of presupposition is to be distinguished from the notion of logical presupposition: a relation between (gappy) propositions which describes when a proposition has a truth value. Our notion is pragmatic, in that it is an aspect of the way sentences behave in contexts, rather than a relation between propositions characterized in many-valued logic. At the same time, it must be stressed that p-infelicity picks out a subclass of pragmatic presuppositions. Not all infelicities are p-infelicities, and not all presuppositional requirements lead to $\mathrm{p}$-infelicities when they are not satisfied. We have argued that bare demonstratives trigger presuppositions which lead to p-infelicity, but we do not insist that all presuppositions have this effect. Presuppositions leading to pinfelicity are basically expressive presuppositions, of the sort highlighted by P. F. Strawson (1950): they are requirements placed on a context for a sentence to express a proposition in that context. Just as p-infelicity is a subspecies of infelicity, this is a subspecies of (pragmatic) presupposition. ${ }^{30[30]}$

A presupposed proposition stands in an unusual relation to the sentence that presupposes it. (When clear enough, we will simply talk about a sentence which expresses a proposition, and talk about entailments between sentences). Consider a nondefective utterance similar to (14):

15. A. That is a fine violin.

B. That is not a fine violin.

C. If that is a fine violin, then we should appreciate it.

P: That picks out a unique contextually salient individual.

${ }^{29[29]}$ This is basically the notion of presupposition of Robert Stalnaker (1974). There is one important difference, however. We are not assuming Stalnaker's account of context and the way contexts satisfy presuppositions. (See note 43 for more discussion.) Also, note that Stalnaker labels what we have called 'presuppositions' as 'presuppositional requirements', as he reserves the term 'presupposition' for a propositional attitude used to describe speaker presuppositions. Our usage is fairly standard among those interested in how certain linguistic constructions lead to presuppositions.

30[30] The classification in terms of logical, expressive, and pragmatic presupposition is due to Scott Soames (1989). Glanzberg (forthcoming b) presents examples of presuppositions whose failures trigger weaker infelicities than $\mathrm{p}$-infelicity. 
Each of $(\mathrm{A}-\mathrm{C})$ implies $(\mathrm{P}) .^{31[31]}$ This is a mark of what is usually called the 'backgroundedness' of presuppositions: presupposed propositions are background for felicitous utterances, and so are insensitive to whether it is a sentence or its negation which is uttered, or whether the sentence appears in a conditional. ${ }^{32[32]}$

We have noted that bare demonstratives trigger presuppositions that lead to $\mathrm{p}$ infelicity. We will say the same for complex demonstratives. To argue this, we need to know more clearly how to detect p-infelicity. Many early discussions of presupposition, notably that of Strawson (1950), linked the relevant notion of felicity to that of truth value. Strawson noted that in many cases of presupposition failure, especially in cases like (14), we are not inclined to say that what was said is true, or that it is false. We are not inclined to assign a truth value. As we mentioned, it is natural to associate this with the lack of a proposition to be true or false.

Unfortunately, the situation is not quite as clear as this explanation suggests. One reason is there is often an option to employ a so-called presupposition-canceling negation. Consider:

16. That is NOT a fine piano - there is nothing there at all. This is a marked construction, but speakers often have it available. We are left wondering if the marked nature of the construction allows it to count as assessing a proposition for

${ }^{31[31]}$ More exactly, if an utterance of A in a context $c$ is true, then it is also true that the use of that in the utterance picks out a contextually salient individual in c. Mutatis mutandis for utterances of $\mathrm{B}$ and $\mathrm{C}$. In this case, the presupposed proposition is about the world of utterance. Not all presuppositions have this feature, however. For instance, consider:

(i)

(i) A. John regrets voting for Bush.

B. John does not regret voting for Bush.

P. John voted for Bush.

Here $(\mathrm{P})$ is not about the world of utterance, and each of $(\mathrm{A}-\mathrm{B})$ implies $(\mathrm{P})$. (In fact, $(\mathrm{A})$ simply entails (P).)

32[32] The family of environments in (15) can provide a useful set of diagnostics for presupposed content. In much of the literature concerned with what contents are presupposed by what sentential constructions, these diagnostics are often offered as virtually definitive of presupposition. They also indicate the basic facts about the projection of presuppositions from their triggers to complex sentences. The literature on these issues is quite large. For an introduction along the lines we pursue here, see Chierchia and McConnell-Ginet (2000). More extensive surveys of recent literature can be found in David Bever (1997) and Nirit Kadmon (2001). 
truth or falsehood. But nonetheless, in uttering (16), speakers appear to say something hard to distinguish from declaring an utterance of (14) to be false. ${ }^{33[33]}$

Luckily, there is some more stable behavior that goes with p-infelicity. Here, finally, we come to two tests that we will shortly employ with uses of complex demonstratives. The first involves what we will call echo-assessments; the second involves indirect speech reports.

An echo-assessment of a sentence $S$ that has already been spoken in a context is a repetition of $S$ (perhaps correcting for occurrences of indexicals like $I$ and you), preceded by either yes or no. In responding to an utterance of (14), speakers (who do not have any misapprehension that there is a demonstrated object) are strongly unwilling to make echo-assessments. They will not say either of:

17. A. \#Yes, that is a fine piano.

B. \#No, that is not a fine piano.

When they do offer a negative judgment, as in (16), they do so by way of initiating a repair, marked by the stressed negation and the gloss on what semantic defect is present in the original utterance. This is the first test for $\mathrm{p}$-infelicity. If an utterance is $\mathrm{p}$ infelicitous, then echo-assessments are unacceptable, without initiating a repair.

The second test involves indirect speech reports. Speakers typically will not offer indirect speech reports that make use of the defective phrase. In response to (14), for example, they will not say simply:

18. \#He said that is a fine piano.

If they do attempt this, they will typically initiate a repair, as in:

19. He said 'that is a fine piano', but I don't know what he was pointing at. That is the second test for $\mathrm{p}$-infelicity. If an utterance is p-infelicitous, then indirect speech report of it is unacceptable, without initiating a repair.

A crucial point about the repairs in these cases is that they are obligatory. The conversation cannot be acceptably continued, in these cases, unless some repair is made. Before speakers in the discourse can comment on the truth of p-infelicitous utterance, or report its content, the utterance must be repaired. Unlike the truth-value test, the need for repair is not made difficult to detect by such devices as presupposition-canceling negation. That just is a repair strategy. We propose that these two tests offer a reliable guide to p-infelicity.

Each of the tests we have proposed targets a central aspect of the notion of proposition expression: propositions are bearers of truth, and propositions are what speakers say. The echo-assessment test targets a proposition expressed by an utterance as the bearer of truth, which determines if the utterance is correct or not. If an echoassessment fails, in a given context, it is because an assessment for truth of what was explicitly said by a speaker cannot be given, without initiating a repair of their attempt to

${ }^{33}{ }^{[33]}$ It may well be that these turn out to be what Laurence Horn (1989) calls 'metalinguistic negation'. We are not committed to any particular analysis of this phenomenon here; we only need to note that constructions like (16) make it difficult to apply the Strawsonsian test for p-infelicity. 
express something. Hence, their attempt was sufficiently defective to preclude truth assessment. This, we suggest, is a central aspect of their having failed to express a proposition at all. This test is thus a more refined version of the traditional test of truth value judgments.

The indirect speech report test targets the second aspect of proposition expression: propositions are what speakers say. If a speaker cannot give an indirect speech report, it is because she cannot appropriately express something the initial speaker might have been attempting to say by the means that speaker used. This occurs if in fact the first speaker's attempt to express a proposition - to determine 'what was said' - failed. As both features - being bearers of truth and being what speakers say - are aspects of the single notion of proposition expression, the tests are typically passed or failed together.

It is important to stress that information from a p-infelicitous utterance may nonetheless reach a knowledgeable interpreter. There are many cases in which information is conveyed which are clearly not cases of expressing a proposition. Consider a sun-burnt man, parched and dirty, who crawls out of the desert, pointing to a pitcher of water and attempting to speak. Too parched, he merely manages to produce a scratchy sound vaguely like:

20. Waa...

By nearly anyone's lights, no proposition is semantically expressed. ${ }^{34[34]}$ But lots of information is available in the act. The act conveys that he man is thirsty, wants water, wants that water, wants it more than to call his wife, etc. Information may be conveyed in all kinds of ways, many of which do not rise to the level of expressing propositions.

There is not the space here to explore fully what this difference amounts to. ${ }^{35[35]}$ But let us simply note that it is important that the issue is one of expressing a proposition, by the assertion of a specific sentence, in a specific context. That can fail, even if there is a proposition that might be charitably attributed to the speaker. This comes out, for instance, when we apply the indirect discourse tests. There may well be cases where the reporter knows fully well what the speaker meant to convey, and can in many cases report it. To apply the test, we need to consider whether the reporter can report what the speaker meant, using her very words (allowing certain small modifications, like changing $I$ to she). It is this which targets whether a proposition was expressed, rather than merely whether information was made available.

We have said that the relevant notion of repair is obligatory repair. This is a normative notion. The norm in question is a norm of discourse, as is appropriate for one that tests for presupposition. Such norms do not operate in a vacuum. If we concoct a case in which a speaker can save a small child from a horrible fate by making an otherwise bad indirect speech report, we may rest assured most decent speakers would do

${ }^{34[34]}$ An exception may be Robert Stainton (1995), who has argued that there are cases of non-sentential assertion; but even Stainton may well not hold that a proposition is expressed in a case like (20), which fails to have even a single lexical item.

${ }^{35[35]}$ Glanzberg (forthcoming a) explores it at greater length. 
it without a second thought. A norm of discourse brings with it a felt unwillingness on the parts of speakers, and a tendency to seek out ways to avoid violations. Repair initiation is a well-established way to do so.

The basic mark of p-infelicity, and the presuppositions which induce it, is obligatory repair. Our tests for p-infelicity are empirical tests, and to give reliable results, they must be applied in good experimental circumstances. There are two dimensions to good experimental circumstances. They concern the epistemic situation of the speakers on the one hand, and their overall normative situation on the other.

First, in good experimental circumstances, the speakers are epistemically wellsituated, so that there is no question about what sentence is uttered, or what the values of its constituents are. If you're behind a curtain and I say Look, he's swallowing fire!, this is not a good circumstance for you to test for whether I have expressed a proposition. What is needed is that you be epistemically well-situated to assess the value if any of the constituents, and in this case, you are not able to assess the value of he. Moreover, it must have been a fully grammatical sentence that was uttered, since a grossly ungrammatical sentence will also require repair, but not for reasons of p-infelicity. (Likewise the utterance must not display any gross phonological or phonetic defects, etc.) Another factor in being epistemically well-situated is that speakers know the rules for when to change words in belief reports, indirect speech reports, or echo-assessments. The rules are clear for when to change $I$ to she or you, for instance. Hence, if B reports A's utterance of I'm hungry, B will say, Yes, you're hungry. ${ }^{36[36]}$

Second, experimental circumstances isolate the relevant discursive norms. In general, to see whether a norm is operative, the influence of competing norms must be screened out, lest they mask the fact that the norm being tested for is violated. In the case of our tests, a very good experimental circumstance is the courtroom setting, where a witness is being asked by a lawyer for an echo-assessment or an indirect speech report. In the courtroom (as we imagine it), there is a clear premium on speaking correctly in the most narrow sense. For the witness on the stand, whether or not what they say is misleading, unhelpful, or irrelevant, is not really their concern. Their obligation is only to speak correctly.

In fact, the courtroom setting is a good experimental circumstance along both dimensions. It makes vivid the assumption that all sentences are well-formed, and all the information needed to determine the values of their constituents is common knowledge. It also makes vivid the screening-off of competing norms. When the tests bear in these cases, they all the better detect the basic matters of whether truth-evaluable information was expressed by the very utterance in question. They all the better detect whether a proposition was expressed.

${ }^{36[36]}$ Note that it is not definitive to being in good experimental circumstances that one can echo-assess and make indirect speech reports without having to repair. If this were so, then the tests would be useless, since what we wanted them for to help us diagnose when repair is obligatory, and so when there is p-infelicity. There seems to be an intuitive notion of epistemic well-situatedness, as illustrated by the curtain case. 
To summarize, when they are applied in good experimental circumstances, our tests provide necessary and sufficient conditions for p-infelicity. But the following caveats must be kept in view. First, the sufficient condition is obligatory repair in the absence of other grounds for repair, such as ignorance of context, phonetic defects, etc. (We might add syntactic or phonological defects as well, but these may amount to failure to produce a well-formed sentence at all, which certainly counts as failure to express a proposition.) Second, the tests allow us to gather empirical evidence for p-infelicity, when they show that speakers take repair to be obligatory in certain settings. As the force of obligatory repair is normative, speakers may not act upon it, if other norms are considered stronger in some occasion. Hence, we proposed, the repair tests should be run in an appropriate experimental setting, such as the courtroom setting. In short, the tests are well tailored to gather evidence for p-infelicity. But they remain tools for gathering evidence, rather than providing an analysis of the phenomenon of failing to express a proposition. When properly applied, the tests detect $\mathrm{p}$-infelicity, and are in this way a sufficient condition. ${ }^{37[37]}$

We now turn to the third step of our argument: applying the tests for $\mathrm{p}$-infelicity to uses of complex demonstratives.

\subsection{P-infelicity in complex demonstratives}

Earlier, we discussed the notion of appropriation. Demonstratives, both bare and complex, require a supplement from the context. In the case of classic perceptual uses of complex demonstratives, the need for a distinctive contextual supplement is illustrated by the existence of contexts in which an utterance of (1) That key is bigger than that key would be felicitous, but (2) The key is bigger than the key would not. We have been neutral on what the nature of this supplement is, offering no more than this functional characterization. But as we discussed in Section 1, some candidates include speaker intentions of some sort, and publically accessible gestures of pointing.

One route to p-infelicity in complex demonstratives is through failure of appropriation. Call this the pre-appropriation route to $\mathrm{p}$-infelicity. This sort of failure leads to genuine $\mathrm{p}$-infelicity. Suppose, for instance, I point at an empty counter and say:

37[37] The comparison between our tests and empirical tests in other areas is straightforward. Suppose we have a test for the presence of some virus in the blood. Suppose the test is difficult to apply. Say it will yield false positives if the sample is contaminated in any way, and false negatives if the sample is drawn from the wrong part of the body. We would certainly conclude we would like to find a better test - one that is easier to apply in the field. But we can still say we know a necessary and sufficient condition for concluding someone has the disease. Likewise, our tools for gathering evidence for $\mathrm{p}$-infelicity are not perfect, as they can produce false negatives or false positives if applied in contaminated conditions. And for a normative notion like obligatory repair, a fully sterile experimental condition may be impossible to find. Nevertheless, evidence that speakers will judge repair to be obligatory is strong evidence for p-infelicity. 
21. \#That key is mine.

I have failed to appropriate anything by my use of that key. Compare this with the case in which I say:

22. \#That is mine.

Both utterances are similarly defective. A speaker will not provide an indirect speech or an echo-assessment for either (21) or (22) without initiating a repair. For example, applying the indirect speech report test to (21) gives:

23. A. \#She said that key is hers.

B. She said 'that key is mine', but I don't know what she meant, because there was nothing there.

The pre-appropriation route to p-infelicity really does lead to p-infelicity. Even so, as pre-appropriation failures are not generally due to the nominal, these are not the crucial cases for policing.

It is the second route to $p$-infelicity that is especially relevant to our defense of nominal policing, so we will focus on it. This route is through appropriation success, where there is an object that the speaker appropriates by her (classic perceptual) use of a complex demonstrative, but it fails to satisfy the nominal. This would be a postappropriation route to $\mathrm{p}$-infelicity. To argue for policing, we have to argue that this really is a route to p-infelicity as well.

Suppose someone at a restaurant is speaking to the waiter. The silverware is in plain view to everyone. Pointing clearly to the fork, the speaker says:

24. \#That knife is dirty.

This is indeed a p-infelicity. Running our diagnostics, we can see that the waiter will be unwilling to offer an echo-assessment. He will not say either:

25. A. \#Yes, that knife is dirty.

B. B. \#No, that knife is not dirty.

Nor will we find indirect speech reports like:

26. \#The person at table 8 said that knife is dirty. [Speaking to the cook.]

The speaker might avoid the issue, by saying:

27. Yes, that [pointing] is dirty.

Or perhaps a repair might be initiated, with:

28. Yes, I see your FORK is dirty. I'll get a new one.

As we have described the case, there is an appropriated object: the fork. We relied upon the pointing gesture to make this clear, but it is not crucial to the case. We might well have appealed to intentions manifested in some other way. But however appropriation happens, there is further reason to think it happens in this case. The further reason is illustrated by non-linguistic behavior. Suppose we have a command following (24), as in:

29. \#That knife is dirty. Bring me a new one!

We have marked infelicity here. It is p-infelicity, as our tests will readily show. But a thoughtful waiter, trying to satisfy his client's desires, will still have no trouble picking up the fork and replacing it. This shows we have appropriation, though we still have pinfelicity. 
What we see here is evidence for nominal policing. The failure of an appropriated object to satisfy the nominal leads to p-infelicity. Failure to satisfy the nominal is thus tantamount to failure to express a proposition. So there is proposition failure in cases in which an appropriated object fails to satisfy the nominal, which is just what nominal policing predicts. Moreover, the requirement that the appropriated object satisfy the nominal behaves precisely as we expect of a presupposition which triggers p-infelicity. We see just as much:

30. A. \#That knife is dirty.

B. \#That knife is not dirty.

C. \#If that knife is dirty, I will make a scene.

We thus conclude that it is a presupposition of sentences with complex demonstratives that the appropriated object satisfy the nominal, and if this presupposition fails, we have p-infelicity. This is nominal policing. ${ }^{38[38]}$

It may be objected that if there is appropriation, then the sentence uttered in fact determines a proposition in context. On this view, and utterance of That $F$ is $G$ is true just in case the appropriated object is G. This objection is in effect to deny the data we have adduced in (25-29).

As we discussed in Section 3.2, the way to bolster our data is to pay closer attention to experimental circumstances, by looking at the 'courtroom' setting. Consider the 'courtroom' version of (24). The lawyer holds up a fork and says to the witness on the stand:

31. Yes or no: this knife killed the victim.

In this case, the witness will find repair obligatory in echo-assessment. We see:

32. \#Yes, that knife killed the victim.

The objection is presumably based on the observation that we can have:

33. Yes, that killed the victim.

This is perfectly acceptable; but it is not an echo-assessment.

There is a strong differential judgment between (32) and (33). (33) is entirely acceptable, while (32) is markedly bad. If the objection where correct, then given that we

${ }^{38}{ }^{[38]}$ Because of the behavior of presuppositions under negation, we do not follow Richard (1993) and Lepore and Ludwig (2000), which predict that That $F$ is $G$ has the same truth-conditions as That is $F$ and $G$ (where the demonstrative in both cases is a device of direct reference). This prediction requires that an utterance of That $F$ is not $G$ be true when the appropriated object fails to satisfy $F$, while we maintain it is a pinfelicity. A slightly more delicate matter is the proposal of Dever (2001), that complex demonstratives map to non-restrictive relative clauses, so That $F$ is $G$ has the truth conditions of That, which is $F$, is $G$. Judgments about these cases are not clear, but with Dever himself, we do not see false non-restrictive relative clauses as inducing p-infelicity. We take this as a reason to doubt that complex demonstratives map to such clauses. We hence believe our proposal is more accurate, and simpler, than Dever's. (Cf. Chierchia and McConnell-Ginet (2000) for an argument that non-restrictive relative clauses do not induce presuppositions.) 
have clear appropriation of the same object in both, we would expect little or no difference between the two. With policing, we predict just the difference we see.

It is worth stressing here that the felicitous (33) constitutes an understated repair, which substitutes a successful bare demonstrative for a defective complex demonstrative in answering (31). A more pronounced repair would be:

34. Well, that is a fork, but that fork did kill the victim.

We thus find, as policing predicts, p-infelicity with the complex demonstrative, but not the bare demonstrative.

It might also be objected that defective utterances containing complex demonstratives such as (24) are p-infelicitous for a different reason than the defective uses of bare demonstratives are. If this is right, then p-infelicity is not the unified phenomenon of failing to express a proposition that we have presented it to be. For instance, it might be suggested that what is bad about (32) is more accurately glossed as its being misleading. But this is at odds with the obligatory nature of the repair. Suppose the witness is a doctor. The doctor knows the fork pierced victim's heart, but by some medical peculiarity, its piercing did not kill the victim. Rather, what killed him was a long-standing liver disease resulting from years of desultory living. The prosecutor may ask (35A), pointedly, and be answered by (35B):

35. A. Yes or no: this fork pierced the victim's heart.

B. Yes, this fork pierced the victim's heart.

Here, the echo-assessment (35B) is highly misleading, as the doctor fully knows. But the repair is not obligatory, and in this setting, (35B) is in no way defective. There is a repair that the doctor might make, to cancel the misleading effect, but it is optional. Optionally, the doctor can say:

36. Yes, this fork pierced the victim's heart...but that did not kill him. The courtroom situation highlights the optional nature of this response. It is unlikely the doctor will make the repair (or be allowed to make it) in this setting.

A closely related objection is that the acceptability of (33) shows that the content of lawyer's question all along was what follows yes in (33). We disagree. What the acceptability of (33) shows is simply that, as in more extreme cases like (20), there is a way to express what appears to be the intent of the lawyer's question. The report in (33) is quite easy to come by, and quite close to the words used by the lawyer, but it remains a different sentence, even if close. It remains a repair. That a different sentence can be an 
accurate representation of what the lawyer had in mind is no more significant than 
extreme cases like $(20) .{ }^{39[39]}$

39[39] There are a number of difficult cases of applying the tests which deserve comment. We will restrict ourselves to one, suggested by Jeff King.

Suppose we are in a knife factory, so salient knives are everywhere. Suppose also there are a few salient forks as well, and a speaker says:

(i) All the forks are dirty.

Finally, suppose there is enough public indication of his intentions that it is clear the speaker intents to talk about the knives.

Intuitively, we would expect no p-infelicity in (i). The domain of quantification is not empty, and the quantifier in (i), it seems reasonable to assume, does not trigger such a presupposition. Nonetheless at least one of our tests is inadvertently tripped. Speakers are at least somewhat unwilling to give echo-assessments in cases like this: some of our informants found it unacceptable to say either:

(ii) A. ?Yes, all the forks are dirty.

B. ?No, all the forks area not dirty.

On the other hand, many of these same people find it fine to give indirect speech reports, with an optional repair, as in:

(iii) He said all the forks are dirty ... but that was not really what he meant.

In light of this case, one might worry that what holds here might hold as well in the case of complex demonstratives - and that would undermine our case for finding $\mathrm{p}$ infelicity when the appropriated object does not satisfy the nominal.

We think that what is important about this sort of case (if these judgments indeed hold firm) is that the two tests come apart. Above, we gave reasons to think the two tests would be passed or failed together, yet here we see a case where one is passed and the other failed. We suspect that what the tests coming apart indicates is that there is too much 'noise' interfering with the tests, rendering what might have seemed to be adequate experimental conditions not good enough. (As with our imagined blood test in footnote 37, we have always granted that applying the tests properly can be tricky.) The 'noise' in this case would be the manifest uncharitability of echo-assessing what the speaker clearly did not mean. This might in effect violate a competing norm, and hence induce a conflict between norms that renders the experimental circumstances unfavorable. (The situation is probably more complicated, though. As Gregory Ward pointed out, there are a number of ways that we can find noise in echo-assessment, depending on just what the speaker takes the point of assessment to be, what the standard of correctness is, etc.) Some speakers do not find this noise interrupts indirect speech report; perhaps because they are simply passing the statement on, and not called upon to evaluate it themselves. Interestingly, we see something similar in another sort of case we do not think yields pinfelicity (though we do not hazard a proposal about what they do): non-restrictive 
There may remain a worry that the problem in (32), and the other policing examples we have considered, do not 'feel' like those in bare demonstrative cases like the original (14). They do not 'feel' like there is no proposition expressed. We suggest that the appearance of a proposition is the misleading result of the ease of the switch from (32) to (33), which obscures the difference, highlighted in (20), between expressing a proposition and making information available. This may return us to the issue we have already discussed, of whether or not to insist that p-infelicity is to be glossed as 'failure to express a proposition' or some other grave defect. But as we said, the two p-infelicity tests target the basic features of the phenomenon in question, whatever its name. In pinfelicitous uses of complex demonstratives, truth value cannot be straightforwardly 
calculated, and what the speaker said cannot be straightforwardly reported. This is evidence for nominal policing. ${ }^{40[40]}$

\section{Communicative smoothness and policing}

So far, we have argued that the strong and the weakened inertness theses are unsustainable, and we have presented evidence in favor of nominal policing. Together, these make a strong case: we must have some policing, and the only way to have it sometimes is to have it all the time.

${ }^{40[40]}$ As empirical means for testing for presupposition, the tests for p-infelicity can be applied to a variety of utterances. A referee raised the question of what results they would give when applied to utterances containing definite descriptions in which the existence condition or the uniqueness condition (or the combination) is not met. The referee objected to our use of the tests on the grounds that (a) the tests deliver the result that utterances of the form The $F$ is $G$, where one or both conditions are not met, are pinfelicitous; but (b) existence and uniqueness conditions of definite descriptions should be treated in the way that Russell proposed, and thus are not presuppositional. Armed with assumption (b), the referee concluded that the correct verdict on such utterances is that they are false, and thus objected that the tests do not test for p-infelicity after all.

We regard it as an open empirical question whether (a) is correct. If it is, then it is strong evidence that definite descriptions carry presuppositions. This contradicts the classical Russellian view (b), though it by no means precludes an analysis where descriptions are restricted quantifiers. (Likewise, it does not imply the classical Strawsonsian view according to which they are simply devices of reference, on par with other such devices.) The presuppositional status of definite descriptions is still widely debated. Firm evidence on (a) would help to resolve this issue, but we are uncertain whether there is such evidence. We thus remain neutral on the status of definite descriptions.

We do not, however, remain neutral about the tests. The tests are a means to gather data, and we offered reasons that they provide data about p-infelicity (viz. the tests target the target the two central roles of propositions: to be bearers of truth-value, and to be what speakers say). We are committed to following the data where it leads, even if this contradicts a Russellian view of descriptions. What would be required not to do so would be a counter-argument that, in spite of our reasons, the tests do not really test for pinfelicity after all.

Though we remain neutral about the ultimate status of definite descriptions, our tests do tell against the position which holds that definite descriptions do not carry presuppositions, and hence do not lead to p-infelicity; and that the correct semantics for complex demonstratives assimilates them to definite descriptions. (Such a position is defended by Lepore and Ludwig (2000). This combination of views is incompatible with what we have argued here, and our defense of the tests is an argument against it. (See note 38 for additional arguments against Lepore and Ludwig's position.) 
But there remain a few cases where policing appears to be too much: the very cases that motivated the inertness theses to begin with. Consider the earlier example (4), repeated here:

4. That badger is hungry.

In the context we described, the fact that the appropriated animal is not a badger, but a fox, does not appear to cause any evident problem. This might tempt one to embrace an inertness thesis. Though we have argued against inertness theses, we would now like to explain why the cases motivating them are not counterexamples to nominal policing, and why they don't support inertness theses as much as they might seem to initially.

Let us begin with a new example. Suppose I am highly knowledgeable about cooking, sharing a kitchen with someone less knowledgeable who confuses colanders and sieves. Pointing to a sieve, she says:

37. The holes in that colander are too small.

I know that the appropriated object is not a colander. So as far as I am concerned, the utterance is markedly odd. But there is an extraordinary measure I can take. I can recognize that my companion has little if any idea what she is talking about, and is misusing the word. I can play along, and even reassure my companion by saying:

38. No, the holes in that colander are just fine. If I say (38), there will be no evident problem with communication. Indeed, I might choose to say (38) for just this reason: communication will proceed as well as it needs to for the purposes at hand if I do.

The communicative smoothness enabled by my utterance of (38) is compatible with p-infelicity. If I play along in this way, pretending to have the same mistaken belief as my interlocutor, I will experience the discomfort that comes from knowingly misusing a word. Although the mistaken interlocutor may not feel it, there is something defective about both utterances (37) and (38). The defect would show up if someone else, who was neither ignorant nor pretending to be, reported the conversation. Suppose, for instance, that I tried to report what my mistaken interlocutor said to someone else. I would not say:

39. \#She said that the holes in that colander are too small. I would not say this, because I would be following the linguistic norm that I suspended for the sake of communicative efficiency in uttering (38). Even in that context, repair is obligatory. The speaker who utters (38), while knowing that the appropriated object is not a colander, in effect trades off the obligation to follow one linguistic norm for the sake of following a competing norm. In this case, the norm of efficient communication wins over the norm obligating repair. ${ }^{41}[41]$

${ }^{41[41]}$ Our guidelines for applying the repair tests tell us to seek good experimental conditions, such as the 'courtroom' setting, where the norm efficient communication is not so prominent. In such a setting, an utterance of (37) would indeed trigger a repair. Suppose the interlocutor is a lawyer, who demands of the witness under oath:

(i) Yes or no: Are the holes in that colander too small?

In such a context, unlike the easygoing one described above, the obligatory nature of the repair is made manifest. 
What about the original fox/badger case (4)? There too, speakers can make do with the utterance of (4), if their epistemic state is such that they cannot distinguish foxes from badgers. They can then simply assume that the animal is a badger, and go on thinking that things are fine. And even if they know too much about what badgers look like to assume this (badgers do not really look like foxes!), speakers may still find it possible to carry on as if the animal was a badger - just as one might, in response to (37), speak as if sieves were called 'colanders'. The crucial point is this: the fact that locally there might be conversational smoothness does not show that there is not a problem with the discourse that would appear in other settings. The norm which obligates repair may be in effect, even if we do not follow it because we are placing a premium on communicative smoothness locally. Local conversational smoothness is not enough to avoid p-infelicity.

Another way to see this point is to consider an extreme case. Suppose two people simultaneously hallucinate a green monster, which seems to both of them to be in the same location. One of them points in a way that would appropriate the monster if it were really there - and in a way that appears to both hallucinators to do just that - and says:

40. \#I am frightened of that.

For the hallucinators, communication is entirely smooth. But it is a rather drastic step to say that a proposition is expressed here. The context is defective enough to refuse to count a proposition as expressed even if the speakers think there is one, and even if it appears locally that they communicate smoothly. That is a reason to think that there is $\mathrm{p}$ infelicity, despite how things seem to the speaker and hearer.

The moral to be drawn here is that not all participants in a conversation will be able to recognize a p-infelicity, and that repair does not cease to be obligatory, simply because there is communicative smoothness. In some cases, the presence of p-infelicity is not enough to impede all aspects of communication. One can get what one needs out of the conversation, even if there is a problem that would become evident in a wider context.

We have argued that the cases motivating inertness theses are not counterexamples to nominal policing. We have not said very much, however, to explain the intuition that the utterances in these cases are true, other than pointing out that they can be met with communicative smoothness, rather than attempts at repair. Much more can be said about what underlies communicative smoothness in these cases, and this will be our focus for the rest of the section.

In (38), the object appropriated by a use of a complex demonstrative does not satisfy the nominal, and the speaker knows it. For cases like these, there is a natural story to tell about the communicative smoothness in terms of the dynamics of conversations. Let us begin with some preliminary remarks.

We think of conversation as a matter of exchanging information. Following Stalnaker $(1974,1978)$ and David Lewis (1979), we think of these exchanges as building a conversational record of information that has been accepted in the course of the conversation, together with whatever background information may also be taken for granted by participants in the conversation. Information is normally added to the record 
by assertion. If the content of an assertion is accepted in the conversation, it is added to the conversational record. ${ }^{42[42]}$

Whatever is in the conversational record becomes common ground among speakers in a conversation. It is common also to think of a context in terms of the accumulated common ground information at a given point in a conversation. The context of an utterance may be thought of as the current common ground - the current state of the conversational record - at the point of utterance. From this perspective, for instance, what the indexical you refers to is a matter of who is taken to be the addressee by speakers, which is a matter of what the common-ground information about the addressee is. We might think of appropriation in these terms as well. What object is appropriated by an utterance might be a matter of what common-ground information about the salience of objects is present in a given utterance. (Though as we discussed in Section 1, we do not adopt this as our official view, for it may preclude a more extensive role for speakers' intentions. As we said there, we wish to remain neutral on this issue.)

It is well-known that there are other ways to add information to a conversational record than assertion. One that is especially important is accommodation. Consider the familiar case of a factive verb:

41. A. John regrets voting for Reagan.

B. John does not regret voting for Reagan.

P. John voted for Reagan.

The presupposition of $(41 \mathrm{~A})$ is $(\mathrm{P})$. If the information that John voted for Reagan $(\mathrm{P})$ is not in a given context - not part of the conversational record - an utterance of (A) may appear infelicitous. It may. But more often, speakers will simply add this information to the context, and move on. This may well induce a sort of 'double-take' feeling, but it will not lead to any genuine infelicity. This is the process of accommodation. As we are describing it, accommodation is a kind of Gricean, on-the-fly repair strategy. To avoid rendering an utterance infelicitous, speakers add the information required by its presuppositions to a context, and proceed as if that information had been there all along. A rather stylized version of this can be seen with clefts, as in the textbook that starts:

42. It was in 1812 that Napoleon fought the battle of Borodino.

${ }^{42[42]}$ Of course, this is an idealization in many ways. Not all conversations are oriented towards building a record of information. Those that are involve more structure, such as a complex structure of turn-taking. But none of these issues affects our point about conversational smoothness and policing. (For a survey of some of these sorts of issues, see Levinson 1983.) 
Such an utterance in a somewhat less direct way conveys the date of the battle. ${ }^{43[43]}$

Presupposition accommodation can happen with complex demonstratives as well. Suppose my car mechanic tells me Your fuel injector is cracked, while pointing to a silvery thing in the engine of my car. Some time later, I am complaining about this, and to make the point, I open the car's hood, point down to the silvery thing and say:

43. That fuel injector is cracked.

This can be perfectly felicitous. Suppose the context provides an appropriated object.

Let us suppose, for instance, that my pointing is clear. Suppose, furthermore, that I did in fact glean the right thing from my mechanic, and what I point to really is a fuel injector. (It could easily have been otherwise. My mechanic could have been pointing to the place where the gasoline spilled out, rather than the fuel injector.)

In this case, both the speaker and hearer have accommodated. Each adds to her store of information that the thing pointed to is a fuel injector. (No doubt, both have highly partial understanding of this proposition, but they can add it nonetheless.) The result is that this proposition becomes common ground among speakers. It becomes information in the context. In the fuel injector case (43), the accommodated proposition is in fact correct. But this is not necessary for the process. The same phenomenon is at work in the colander/sieve case (38), when the speaker knows that the appropriated object is not a colander but for present purposes decides to speak as if it is. The speaker might have been inclined to take what colanders are as common ground, in a cooking setting. But she might now revise this supposition, adding information in the common ground that she knows to be false - namely, that the object in question is a colander. There is no general requirement that information in a conversational record be true. This is asking too much. Nor is there even a requirement that all speakers believe it. It is possible to go along with a conversation, even if one does not believe what is said.

Summing up, the communicative smoothness in the cases motivating the inertness theses is explained as follows. What appears to impede smooth communication, as far as speakers in the conversation are concerned, is the information contained in the context. Impairment can be avoided by such strategies as accommodation, which is a way of adjusting this information. We have argued that this can take place in spite of grave semantic defects in an utterance: in spite of p-infelicity. Thus, if the situation is right, the

43[43] We are treating this sort of accommodation as type of conversational repair, inducing what is sometimes glossed as the phenomenon of 'informative presupposition'. This is fairly close to Lewis's original use of the term, and may well be close to Stalnaker's treatment as well (see Simons 2003 for more discussion). In more recent literature, such as van der Sandt (1992), accommodation is more closely allied with projection mechanisms.

Factive presuppositions are discussed at length by Stalnaker (1974). Clefts have been the subject of much discussion, including Atlas and Levinson (1981), Delin (1992), and Glanzberg (forthcoming b). 
norm of repair can be overridden to preserve communicative smoothness. But, we have argued, there is p-infelicity nonetheless. ${ }^{44[44]}$

\section{Conclusion}

Complex demonstratives in their classic perceptual uses are standardly taken to be paradigmatic referring expressions. If the nominal in such uses of complex demonstratives plays a policing role, this does not mitigate against the standard categorization of complex demonstratives as referring expressions, as other defenders of nominal policing have pointed out (e.g. Braun 1994; Borg 2000).

We said at the start that our defense of nominal policing, unlike previous ones, leaves it open whether complex demonstratives are devices of reference or not. But it may initially seem mysterious how they could fail to be such devices. How, for example, could complex demonstratives plausibly be thought to be quantificational?

44[44] Throughout, we have treated nominal policing as the thesis that the object appropriated by a use of a complex demonstrative must satisfy the nominal, in order for the utterance in which it occurs to express a proposition. We have argued that this thesis is true in virtue of the presuppositional behavior of complex demonstratives. Some linguists and philosophers (such as Stalnaker 1974, 1978) hold a view of presupposition that would in effect recast nominal policing in epistemic terms. This view builds on the idea of context as common-ground information. According to it, the only issue for satisfaction of presuppositional requirements is whether the information in a context entails a presupposition. (Propositional presuppositions, such as those of factives like (41), are naturally treated this way.) If we treated policing this way, it would be recast as an epistemic thesis: a nominal would count as satisfied in a case in which all speakers accept a mistaken proposition.

In explaining problematic examples like (4) and (37), we have in effect noted that this more epistemic approach is useful in explaining phenomena of conversational smoothness. But we have also noted that in some cases, this smoothness is the result of a kind of pretense. In (39), for instance, the accommodating speaker finds uses of that colander marked, and cannot make them outside of the highly localized context.

Though we have not argued against this more epistemic view as a basis for approaching the wide range of presuppositional phenomena, we have in essence argued that it is not adequate for the presuppositions of demonstratives. We think this is fairly clear in hallucination cases like (40). More generally, we have suggested that even when the participants in a given conversation do not recognize a defect in their commonground information, and so do not recognize p-infelicity, it may be present nonetheless. As we noted in discussing (39), the infelicity may still be brought to light in wider conversational settings, where speakers not entertaining the same propositions are involved. Generally, though speakers need not believe all the propositions in a conversational record, gross errors in the record, or asymmetry in speakers attitudes, can constitute defects in a context which can generate p-infelicity. 
Jeffrey King (2001a. Ch. 2) has recently defended a view according to which, in a context of utterance, that in that $F$ contributes a two-place relation between properties to the semantic value of utterance in which it occurs, just as the contributions of some, every, one, and other generalized quantifiers are thought to do. (It is not unproblematic what makes an expression a quantifier; King points to several syntactic and semantic features that complex demonstratives, on his view, share with paradigmatic quantifiers.) According to King, the lexical meaning of that in that $F$-its meaning, considered outside of any context - is a function from properties and context to a truth value. Where blanks are placeholders for properties, King thinks that the proposition expressed by an utterance of That $F$ is $G$ is structured in the following way:

44. and _ are uniquely in an object $x$ and $x$ is

The first and last blank are filled in by $\mathrm{F}$ and $\mathrm{G}$, respectively. How the middle two blanks are filled depends on whether the use of that $F$ is rigid or not.

We have been concerned exclusively with classic perceptual uses, which are rigid, so let us focus on those. When the use of that $F$ is a classic perceptual use (and so is rigid), the second blank is filled with the property of being identical to the appropriated object, and the third blank is filled with the property of being jointly instantiated in the context. The second blank is needed, King thinks, to account for what we have called appropriation. Call this blank the proposition's appropriation position.

Let us see what a simple example looks like on King's view. Suppose someone utters:

45. That fox in the garbage is hungry.

Suppose the object appropriated by the use of that fox in the garbage is the creature Frida. Then the property filling in the appropriation position is the property of being identical to Frida, and the entire proposition, according to King, will be:

46. FOX IN GARBAGE and =FRIDA are uniquely jointly instantiated in $c$ in an object $x$ and $x$ is HUNGRY.

(Here $c$ stands for the context of utterance, and capitals indicate properties.)

Now, with respect to nominal policing, King's account is silent. King's account leaves open what happens if there is no unique thing that is both Frida and a fox in the garbage. It leaves open whether an utterance in such a context is straightforwardly false, or fails to express a proposition. But the latter option could easily be written into King's semantics, without spoiling the status of the expression as a quantifier. This would simply be a matter of appending a clause that says there is a presupposition that there is a unique object that has both $\mathrm{F}$ and the property in the appropriation position. ${ }^{45[45]}$

If such a presupposition were added to King's semantics, the result would be a quantificational account of complex demonstratives in which the nominal plays a

45[45] That generalized quantifiers can carry presuppositions has been well-known for some time, certainly since the work of Barwise and Cooper (1981). 
policing role. ${ }^{46[46]}$ This illustrates the neutrality of our defense of nominal policing. If our defense works, then complex demonstratives (at least when used in the classic perceptual way) carry a presupposition that the appropriated object satisfies the nominal. But the fact that these uses carry such a presupposition places no constraints on whether the expression is a device of direct reference, a device of reference of some other sort, a quantifier $\grave{a}$ la King, or something else. ${ }^{47[47]}$ The presuppositions that we have argued complex demonstratives carry do not map on to any particular semantic category.

Suppose that the nominal in classic perceptual uses of complex demonstratives plays a policing role, but that these expressions are either quantificational, or are discourse anaphors in dynamic semantics. This would be an interesting combination of features for these expressions to have: they would not be devices of direct reference, or of reference of the sort that Evans (1982) and McDowell (1984) take demonstratives to exemplify. ${ }^{48[48]}$ Yet they would retain the main marks of referring expressions: they would be rigid; they would involve a rapport between speaker and object; and they would be object-dependent, in that if nothing is appropriated by the speaker's use of the expression, then the utterance in which it occurs will lack a truth value. Of course, it is not news that expressions can be rigid, or sometimes require special rapport between speaker and thing spoken about, even if the expression is not a device of reference. What may be more surprising is that an expression (or some uses thereof) can be objectdependent, without being a device of reference, and without including any such device as a part. (A direct reference theorist would predict object-dependence for utterances of Something identical with that, but would not expect a quantifier phrase to be able to be object-dependent when it did not include any directly referential expressions.) The compatibility of our account of nominal policing with a wide range of different semantics for what many consider to be paradigmatic referring expressions brings this surprising fact into focus.

We conclude on a speculative note. Referring expressions are typically taken to have three features essentially: rigidity, object-dependence, and structural simplicity.

${ }^{46[46]}$ Nominal policing is compatible with the view (call it nominal stalking) that for an utterance of That $F$ is $G$ to be true with respect to a world the appropriated object has to be F in that world - and not merely in the context of utterance. (So if nominal policing is true and nominal stalking false, then with respect to a world in which Frida is not by the garbage, an utterance of (45) would be true, so long as in that world, Frida, wherever she is, is hungry.) Braun (1994) and Borg (2000) defend nominal policing and deny nominal stalking. Richard (1993) endorses nominal stalking. We argued against it in note 38. King's account of rigid uses of complex demonstratives denies nominal stalking as well. ${ }^{47[47]}$ For instance, Roberts' (2002) dynamic treatment of complex demonstratives makes them a subspecies of definite noun phrases, all of which are treated as discourse anaphors in a dynamic framework.

${ }^{48[48]}$ The way Evans and McDowell think of such expressions, they have de re Fregean senses. 
Armed with this assumption about what it is to be a referring expression, philosophers have typically taken the distinction between referring and quantificational expressions to be exclusive. ${ }^{49[49]}$ Our speculative suggestion is that the interesting semantic category in the vicinity may rather be one that overlaps with quantificational expressions, rather than one that excludes them. If complex demonstratives turn out to be quantificational in the way that King has proposed, then given our arguments for nominal policing, there will be quantificational expressions that have the first two of these properties (rigidity and object-dependence). ${ }^{50[50]}$ They would not count as referring expressions on the typical characterization of such expressions, but that would only be due to their structural complexity. More generally, if there turn out to be rigid and object-dependent quantificational expressions, then structural simplicity alone would have to bear the entire weight of making the distinction between quantificational and referential expressions exclusive. Why think simplicity could bear so much weight? In particular, if structural simplicity turns out to be something like syntactic simplicity at the level of logical form, why think it is adequate to decide whether a phrase belongs to one semantic category or another? We speculate that it could not. Whether or not the speculation is correct, the case of complex demonstratives suggests that it is worth investigating.

49[49] According to Stephen Neale's (1993) "dilemma hypothesis," every singular term is either a quantificational expression or a referring one, where referring expressions are taken to be unstructured, and the categories are exclusive. King (2001b) agrees that the distinction is exclusive, but questions whether it is exhaustive. There has been a surge of recent discussion of Neale's hypothesis in connection with complex demonstratives: Borg (2000) and Dever (2001) both argue that the case of complex demonstratives seems to make trouble for this hypothesis, on the grounds that these expressions have semantically significant structure (for Borg, this is a consequence of nominal policing). Neither rejects the dilemma hypothesis in the end, though for different reasons. (Borg concludes that the notion of what a referring expression is should be expanded, while Dever concludes that complex demonstratives have a great deal of underlying syntactic and semantic structure.) If our speculative hypothesis turns out to be correct, then while complex demonstratives pose a problem for the dilemma hypothesis (as Borg and Dever suggest), the moral to be drawn may be rather than referring expressions do not constitute a semantic category distinct from quantificational expressions.

50[50] The quantificational expression Every friend of Frida may be object dependent thanks to the name Frida, but if so it is not object dependent in the relevant way. Its object dependence simply derives from the object dependence of the name Frida and the compositional semantics of the phrase. The object dependence with we are concerned, in contrast, is not simply due to a sub-constituent being object dependent and contributing its value to compositional semantics. So, for instance, on King's theory of complex demonstratives, modified as propose to institute policing, we find object dependence but not because of the object dependence of any sub-constituent. 


\section{References}

Atlas J. D. and S. C. Levinson, 1981. It-clefts, informativeness, and logical form: Radical pragmatics (revised standard version). In P. Cole (ed.), Radical Pragmatics. New York: Academic Press.

Austin, J. L., 1975. How to Do Things with Words, $2^{\text {nd }}$ ed. Cambridge: Harvard University Press.

Barwise J. and R. Cooper, 1981. Generalized quantifiers and natural language. Linguistics and Philosophy 4: 159-219.

Bever, D. I., 1997. Presupposition. In J. van Benthem and A. ter Meulen (eds.), Handbook of Logic and Language, pp. 939-1008. Amsterdam: Elsevier.

Borg, E., 2000. Complex demonstratives. Philosophical Studies 97: 229-249.

Braun, D., 1993. Empty names. Nous 27: 449-469.

- 1994. Structured characters and complex demonstratives. Philosophical Studies 74: 193-219.

Chierchia, G. and S. McConnell-Ginet, 2000. Meaning and Grammar, $2^{\text {nd }}$ ed. Cambridge: MIT Press.

Davies, M., 1982. Individuation and the semantics of complex demonstratives. Journal of Philosophical Logic 11: 287-311.

Davis, S. (ed.), 1991. Pragmatics. Oxford: Oxford University Press.

Delin, J., 1992. Properties of it-cleft presupposition. Journal of Semantics 9: 289-306.

Dever, J., 2001. Complex demonstratives. Linguistics and Philosophy 23:271-330.

Donnellan, K., 1966. Reference and definite descriptions. Philosophical Review 75: 281-304. Reprinted in Davis (1991).

Dummett, M., 1959. Truth. Proceedings of the Aristotelian Society 59: 141-162. Reprinted in Dummett (1978).

—, 1978. Truth and Other Enigmas. Cambridge: Harvard University Press.

Evans, G., 1982. The Varieties of Reference. Oxford: Oxford University Press. 
Glanzberg, M., forthcoming a. Against truth-value gaps. Forthcoming in J. C. Beall (ed.), Liars and Heaps: New Essays on Paradox. Oxford: Oxford University Press.

- forthcoming $b$. Presuppositions, truth values, and expressing propositions. Forthcoming in G. Preyer and G. Peter (eds.), Contextualism in Philosophy. Oxford: Oxford University Press.

Grice, H. P., 1975. Logic and Conversation. In P. Cole and J. Morgan (eds.), Speech Acts, vol. 3 of Syntax and Semantics. New York: Academic Press. Reprinted in Grice (1989).

— 1989. Studies in the Ways of Words. Cambridge: Harvard University Press.

Heim, I., 1983. On the projection problem for presupposition. In M. Barlow, D. Flickinger, and M. Westcoat (eds.), Proceedings of the West Coast Conference on Formal Linguistics 2, pp. 114-125. Reprinted in Davis (1991).

— 1990. E-type pronouns and donkey anaphora. Linguistics and Philosophy 13: $137-177$.

Horn, L. R., 1989. A Natural History of Negation. Chicago: University of Chicago Press.

Kadmon, N., 2001. Formal Pragmatics. Oxford: Blackwell.

Kaplan, D., 1977/1989. Demonstratives. In J. Almog, J. Perry, and H. Wettstein (eds.), Themes from Kaplan, pp. 481-563. Oxford: Oxford University Press. This is the first publication of a widely circulated manuscript dated 1977.

Karttunen, L., 1974. Presupposition and Linguistic Context. Theoretical Linguistics 1: 181-194. Reprinted in Davis (1991).

Kennedy, C. 1997. Projecting the Adjective: The Syntax and Semantics of Gradability and Comparison. PhD Thesis, University of California, Santa Cruz. Published by Garland Press, New York 1999.

King, J. C., 1999. Are 'that' phrases devices of direct reference? Nous 33: 155-182.

— 2001a. Complex Demonstratives. Cambridge: MIT Press.

— 2001b. Remarks on the syntax and semantics of day designators. Philosophical Perspectives 15: 291-333. 
Larson, R. and G. Segal, 1995. Knowledge of Meaning. Cambridge: MIT Press.

Lepore, E. and K. Ludwig, 2000. The semantics and pragmatics of complex demonstratives. Mind 109: 199-240.

Levinson, S. C., 1983. Pragmatics. Cambridge: Cambridge University Press.

— 2000. Presumptive Meanings. Cambridge, MIT Press.

Lewis, D., 1979. Scorekeeping in a language game. Journal of Philosophical Logic 8: 339-359. Reprinted in Davis (1991).

McDowell, J., 1984. De re senses. Philosophical Quarterly 34: 283-294. Reprinted in McDowell (1998).

- 1998. Meaning, Knowledge, and Reality. Cambridge: Harvard University Press.

Neale, S., 1993. Term Limits. Philosophical Perspectives 7: 89-123.

Richard, M., 1993. Articulated terms. Philosophical Perspectives 7: 207-230.

Roberts, C., 2002. Demonstratives as definites. In K. van Deemter and R. Kibble (eds.), Information Sharing, pp. 89-136. Stanford: CSLI Publications.

Schiffer, S., 1981. Indexicals and the Theory of Reference. Synthese 49: 43-100.

Siegel, S., 2002. The role of perception in demonstrative reference. Philosophers' Imprint 2 (1).

Simons, M., 2003. Presupposition and accommodation: Understanding the Stalnakerian picture. Philosophical Studies 112: 251-278.

Soames, S., 1989. Presupposition. In D. Gabbay and F. Guenthner (eds.), Handbook of Philosophical Logic, pp. 553-616. Dordrecht: Kluwer.

Stainton, R., 1995. Non-sentential assertions and semantic ellipsis. Linguistics and Philosophy 18: 281-296.

Stalnaker, R. C., 1974. Pragmatic Presuppositions. In M. K. Munitz and P. K. Unger (eds.), Semantics and Philosophy. Reprinted in Stalnaker (1999). 
— 1978. Assertion. In P. Cole (ed.), Pragmatics, vol. 9 of Syntax and Semantics. Reprinted in Stalnaker (1999).

— 1999. Context and Content. Oxford: Oxford University Press.

Strawson, P. F., 1950. On Referring. Mind 59: 320-344. Reprinted in Strawson (1971).

— 1971. Logico-Linguistic Papers. London: Methuen.

Taylor, B. 1981. Truth-theory for indexical languages. In M. Platts (ed.), Reference, Truth and Reality: Essays on the Philosophy of Language. London: Routledge and Kegan Paul, 183-98.

van der Sandt, R. A., 1992. Presupposition projection as anaphora resolution. Journal of Semantics 9: 333-377. 